\title{
Effects of Water Samples in Polyethylene Terephthalate Bottles Stored at Different Conditions on Zebrafish Embryos with Relevance to Endocrine Disrupting Chemical Migration and Adenomatous Polyposis Coli Tumor Suppressor Gene
}

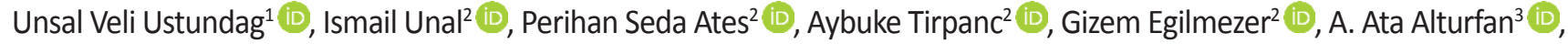 \\ Turkan Yigitbasi $^{1}$ (D) Ebru Emekli-Alturfan ${ }^{2}$ (D) \\ ${ }^{1}$ Istanbul Medipol University, Faculty of Medicine, Department of Biochemistry, Istanbul, Turkey \\ ${ }^{2}$ Marmara University, Faculty of Dentistry, Department of Biochemistry, Istanbul, Turkey \\ ${ }^{3}$ Istanbul University, Faculty of Cerrahpasa Medicine, Department of Biochemistry, Istanbul, Turkey \\ Correspondence Author: Ebru Emekli-Alturfan \\ E-mail: ebruemekli@yahoo.com \\ Received: $02.08 .2018 \quad$ Accepted: 25.09.2018
}

\begin{abstract}
Objective: Polyethylene terephthalate (PET) is a material that is most commonly used for production of clear plastic bottles. Adenomatous polyposis coli (APC) and $\beta$-catenin have been related with cancer. Aim was to investigate the effects of PET bottled water samples that were exposed to sunlight and hot water on zebrafish embryos. Moreover the effects of these water samples on APC knockdown zebrafish embryos were also evaluated. Methods: Phthalate concentrations in water samples were determined using ELISA. Immunohistochemical method and RT-PCR were used to analyse the expressions of proliferative cell nuclear antigen (PCNA), $\beta$ catenin, Wnt $3 a$ and Gsk3 $\beta$. Biochemical parameters were measured using spectrophotometric methods. Vitellogenin concentrations were measured using ELISA and apoptotic cells were evaluated by Acridine Orange staining.

Results: Increased PCNA, $\beta$-catenin, Wnt 3a, Gsk3 $\beta$ expressions, vitellogenin, nitric oxide, apoptosis and impaired oxidant-antioxidant balance were observed in the exposure groups with these increases being more profound in APC knockdown groups.

Conclusion: APC knockdown embryos were more prone to the deleterious effects of water samples used in this study.

Keywords: Polyethylene terephthalate, phthalates, Wnt/ $\beta$-catenin signaling, adenomatous polyposis coli
\end{abstract}

\section{INTRODUCTION}

The issue on the potential effects of endocrine disrupting chemicals (EDCS) on public health revealed the need for new research into the mechanisms of their effects in case of exposure. EDCs are defined as synthetic or natural molecules in the environment, they can impair endocrine functions and they are suspected carcinogens. EDCs can be detected in different products such as bottles, canned waters, storage boxes as well as treated waste water and they can be categorized as pesticides, plasticizers, industrial side products, pharmaceuticals, flameretardants, phytoestrogens, or heavy metals. EDC exposure during development is a serious and major health concern and may lead to permanent or longlasting defects (1-3).

Polyethylene terephthalate (PET) is a widely used material for the production of clear plastic bottles to sell water. They are also used to produce soda beverages, sports drinks, vinegar containers and for cosmetic products packaging. On the other hand the potential of plastic materials from packagings to migrate EDCs into foods and beverages has been a neglected isssue for long (4). Phthalates are a group of chemicals that are used to provide flexibility and durability to plastics and chemically they are the diesters of 1,2-benzenedicarboxylic acid, known as phthalic acid. Phthalates have been related with different adverse outcomes including adiposity and insulin resistance $(5,6)$, anogenital distance decrease (7) and alterations in sex hormone levels (8). Other consequences of phthalates have been reviewed by Hauser and Calafat (9). Being as the most commonly used plasticizer di-[2ethylhexyl]-phthalate (DEHP) has been reported to lead to reproductive and developmental toxicity (10). Migration is defined as leaching of chemicals from food packaging into food. Although this is systematically checked by market authorizations storage conditions and the effects of acidic or alkaline foodstuffs, UV light, and heat may degrade polymers. Leaching of monomers as a result of this process is also known as "release"(11).

Adenomatous polyposis coli (APC) gene produces the APC protein which plays critical roles in many cellular processes. The roles of APC protein include its tumor suppressor function, control on cell division, cell attachments and movements. The APC protein works with beta-catenin through Wnt/ $\beta$-catenin pathway in association with other proteins (12). Mutations in the $A P C$ gene has been shown to lead to uncontrolled proliferation in intestinal epithelial cells and are related with the earliest colorectal carcinogenesis stages (13). On 
the other hand although the role of Wnt/ $\beta$-catenin signaling in embryonic development and tissue homeostasis has been evaluated in some studies, the relationship between abnormalities in Wnt ligands and tumorigenicity has not yet been clarified (14).

In recent years zebrafish embryo has become a popular model due to its external and rapid development, small size, high level of fecundity and optical transparency (15). In the current study we tested the hypothesis that APC knockdown zebrafish embryos are more susceptive to the deletious effects of water samples that had been heated in PET bottles to simulate the release of chemicals due to storage conditions. Accordingly expressions of $\mathrm{Wnt} / \beta$-catenin pathway proteins, vitellogenin levels, apoptosis and oxidant-antioxidant status of zebrafish embryos have been evaluated.

\section{METHODS}

\subsection{Maintenance of zebrafish}

Wild type $A B / A B$ Strain were maintained in apparently disease-free conditions, kept in the aquarium rack system (Zebtec, Tecniplast, Italy) at $27 \pm 1^{\circ} \mathrm{C}$ under a light/dark cycle of $14 / 10 \mathrm{~h}$. Zebrafish were fed twice a day with commercial flake fish food supplemented with live Artemia. Reverse osmosis water that was added $0.018 \mathrm{mg} \mathrm{L}^{-1}$ Instant Ocean ${ }^{\mathrm{TM}}$ salt was used for all experiments. After natural spawnings, embryos that were fertilized were collected cultured, and staged by developmental time and morphological criteria as described previously (16). This study was approved by the Marmara University Animal Experiments Local Ethics Committee (138.2013.mar; 28.04.2014).

\subsection{Preparation of water samples}

Commonly used bottled water samples were randomly selected from supermarkets in Istanbul, Turkey. The first group consisted of PET bottles that were kept under sunlight for 30 days in July. The second group consisted of PET bottles that were filled with $100{ }^{\circ} \mathrm{C}$ boiled water and allowed to cool in them. Water samples from these bottles were used for the exposure groups in petri dishes (volume: $40 \mathrm{ml}$ ). Embryos were added to each dish and placed into the incubation chamber and examined for 120 hours.

\subsection{Embryo exposures}

For the exposure experiments, embryos were exposed to the water samples in well plates for 120 hours after fertilization (hpf). In order to evaluate development, mortality and hatching parameters the group were prepared as three replicate wells. Each group contained 20 embryos. The exposure solutions were prepared every day as fresh solutions. When the exposure period ended, the embryos were washed with embryo medium for several times and they were allowed to develop until $120 \mathrm{hpf}$. A stereomicroscope (Zeiss Discovery V8, Hilden, Germany) was used for the detection of developmental parameters. Malformation images were recorded. The rates of mortality and hatching were determined for every $24 \mathrm{~h}$. The hatching rate is defined as the ratio of hatching embryos to the living embryos in a well.

\subsection{Phthalates Analyses in Water Samples}

Phthalates were measured using the phthalates Elisa kit (Abraxis Phthalates ELISA, Microtiter Plate, Katalog No: 530050, Railroad Drive, Warminster,USA) which is a direct competitive ELISA method that is based on the recognition of total phthalates by antibodies. The concentrations of phthalates in the samples are evaluated by interpolation using the standard curve constructed with each run. Using the absorbances at $450 \mathrm{~nm}$, a dose-response curve was obtained from known concentrations of phthalates standards and the BPA concentration in the samples $(n=7)$ were calculated using the absorbances obtained from the standard curve.

\subsection{Morpholino Microinjections}

Morpholino oligonucleotides were maintained from Gene Tools LLC. APC and (5'-TAGCATACTCTACCTGTGCTCTTCG-3') the control morpholino (5'-CCTCTTACCTCAGTTACAATTTATA-3') were dissolved in $1 \mathrm{mM}$ in $1 \times$ Danieau buffer. $0.5 \mathrm{mM}$ morpholino was injected into wild type embryos that were at one - four cell stages for the microinjections $(17,18)$.

\subsection{Expression Analyses}

\subsubsection{Whole Mount Immunohistochemistry}

For whole-mount immunohistochemical expression of proliferative cell nuclear antigen (PCNA), $\beta$-catenin and Wnt 3a zebrafish embryos were fixed. Pronase $(2.0 \mathrm{mg} / \mathrm{ml}$, in $\mathrm{E} 3$ medium; $5 \mathrm{mM} \mathrm{NaCl}, 0.17 \mathrm{mM} \mathrm{KCl}, 0.33 \mathrm{mM} \mathrm{CaCl}_{2}, 0.33 \mathrm{mM}$ $\mathrm{MgSO}_{4}$ ) was used to dechorionate embryos for 3 to $5 \mathrm{~min}$ and then they were rinsed five times in E3 medium. They were incubated for 1 hour in $4 \%$ paraformaldehyde and Anti-PCNA antibody, Anti- $\beta$-Catenin antibody, Anti-Wnt 3a antibody (abcam ab28472; abcam ab6302 and abcam ab29 respectively) were used as primary antibodies.

\subsubsection{Reverse Transcription (cDNA synthesis) and Quantitative Real-Time PCR}

Rneasy Mini Kit and Qiacube (Qiagen, Hilden, Germany) were used for the isolation of RNA from the embryos according to the manufacturer's instructions. After that single-stranded cDNA was produced from $1 \mu \mathrm{g}$ of total RNA using $\mathrm{RT}^{2}$ Profiler PCR Arrays (Qiagen). DNA Master SYBR Green kit (Qiagen) was used for PCRs. The expression of cyclin D1, c-myc, $B$ actin, wht $3 a$ and $g s k 3 b$ were evaluated by quantitative RT-PCR using the Qiagen Rotor Gene-Q Light Cycler instrument (Qiagen, Hilden, Germany). The average values were calculated based on the results of three experiments. DDCT method was used 
normalizing the values with the house keeping gene $b$ actin (19).

\subsection{Determination of Vitellogenin levels}

Vitellogenin levels were determined at the end of 120 hours in zebrafish embryos by the Zebrafish Vitellogenin Elisa Kit (Biosense, Prod No: V01008402,Michigan, USA). For whole body homogenates, 50 embryos were homogenized in 500 $\mu \mathrm{L}$ PBS. Then whole body homogenates were 1:500 diluted (5 $\mu \mathrm{L}$ homogenate and $2495 \mu \mathrm{L}$ dilution buffer) according to the manufacturer's instructions. Each group was prepared as five replicates. This assay is based on the use of specific binding between antibodies and vitellogenin to measure vitellogenin in the samples.

\subsubsection{Biochemical Assays}

Zebrafish embryos at $72 \mathrm{hpf}$ were used ( $\mathrm{n}=5,100$ individuals per pool). The embryos were then homogenized in $1 \mathrm{ml}$ PBS, which was followed by centrifugation. The forming supernatant was used for the biochemical assays.

\subsubsection{Total Protein Determination}

Total protein concentrations were measured according to the method of Lowry (20). For this method, alkaline proteins were reacted with copper ions and then they were reduced by the Folin reactive. A spectrophotometer was used to evaluate the absorbance of the product at $500 \mathrm{~nm}$. The results were calculated and expressed as levels per protein.

\subsubsection{Lipid Peroxidation Determination}

Malondialdehyde (MDA) is the end product of lipid peroxidation (LPO) and the method of Yagi (21) was used to determine MDA concentrations. The MDA results were presented as $\mathrm{nmol} \mathrm{MDA} / \mathrm{mg}$ protein using the extinction coefficient of $1.56 \times 10^{5} \mathrm{M}^{-1} \mathrm{~cm}^{-1}$.

\subsubsection{Nitric Oxide Determination}

Nitric oxide (NO) levels were assessed using the method based on reducing nitrate to nitrite by vanadium (III) chloride (22). In this method, nitrite and sulfonylamide reacts with $\mathrm{N}$-(1-Naphtyl) ethylenediamine dihydrochloride in an acidic media and as a result diazonium compound is produced. The absorbance of the colored complex was measured at $540 \mathrm{~nm}$ using spectrophotometer and results were calculated and presented as nmol NO/mg protein.

\subsubsection{Glutathione-S-transferase Determination}

Glutathion-s-transferase (GST) activity was evaluated using the method based on GSH and 1-chloro-2,4-dinitro-benzenin
(CDNB) conjugation and the absorbance of their product at $340 \mathrm{~nm}$ (23).

\subsubsection{Determination of Apoptosis}

Apoptosis of live embryos was determined at $72 \mathrm{hpf}$ using acridine orange (Sigma, Darmstadt, Germany) staining method (24). Accordingly, live embryos that were immersed for $10 \mathrm{~min}$ at room temperature, in $5 \mathrm{\mu g} / \mathrm{ml}$ acridine orange a nucleic acid-selective metachromatic stain. After that embryos were washed in E3 medium. Then the embryos were anesthetized using Tricaine for $3 \mathrm{~min}$. Embryos were visualized and imaged for less than 1 minute, apoptotic cells were determined using fluorescence microscope (Zeiss V16 Axio Zoom microscope-546 nm filter, USA).

\subsubsection{Statistical analysis}

One-way Anova with post-hoc Tukey's Multiple Comparision Test was used to analyse the differences between normally distributed data (Shapiro-Wilk normality test), using Graph Pad 6, A p value of $\leq 0.05$ was considered as significant.

\section{RESULTS}

In order to examine the hypothesis that APC knockdown embryos were more prone to the possible deleterious effects of chemicals that leach from PET bottles and DEHP, we aimed to to knock down the function of APC and evaluate the effects of exposure to the water samples kept in PET bottles on both control and APC knock down embryos. To achieve this, a morpholino that is splice blocking specific for $A P C$ that targets the splicing of $A P C$ between exon 15 and intron 15 was designed as previously shown (25). At the one - or two-cell stage this APC morpholino was injected this into wild type zebrafish embryos. The intron-retained RNA transcript was produced as shown by the expression levels of the reported $\beta$-catenin target genes, $c$-myc (26) and cyclin $D 1(27)$ that are expected to be up-regulated following $A P C$ knockdown. We observed the malformations in the $A P C$ morphant embryos such as pericardial edema, tail and pigmentation defects (Figure 1A). Accordingly increased expressions of c-myc and cyclin D1 were confirmed by quantitative RT-PCR (Figure 1B). Immunohistochemical results revealed the elevated cellular $\beta$-catenin staining in the neural tube, notochord and eye region which indicates clonal loss of APC function in the MO group. The expression of PCNA was evaluated as a proliferation marker and in neural tube and eye intense staining revealed elevated expression in the $\mathrm{MO}$ group. $\mathrm{MO}$ injected embryos also presented more intense Wnt 3a staining in eye, brain, neural tube, notochord, somites, dorsal, caudal and anal fins (Figure 1C). 


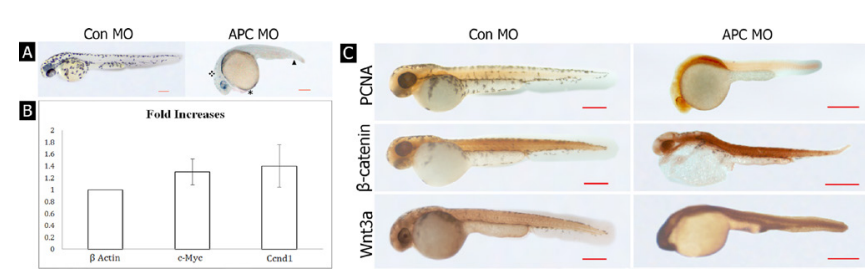

Figure 1. A) Phenotypes of Control Morpholino (Con MO) and APC Morpholino (APC MO) *pericardial edema, $\Delta$ tail defect, $\square$ * pigmentation defect $B$ ) Quantitative RT-PCRwith primers specific for B-actin, c-Myc, and Ccnd1 was performed on CDNAs obtained from embryos injected with control or APC morpholinos, expressed as fold increases. C) PCNA, B-catenin and Wnt $3 a$ expressions in Con MO and APC MO group; Con: Control, APC: Adenomatous polyposis coli, PCNA: Proliferative cell nuclear antigen

The mortality rate increased and hatching rate decreased significantly in the APC morphant embryos compared with the Con MO group. Significant increases in mortality rates and decreases in hatching rates were observed in the $30 \mathrm{~d}$ Sun PET and PET $100{ }^{\circ} \mathrm{C}$ groups when compared with the Con $\mathrm{MO}$ group. On the other hand, mortality rates increased and hatching rates decreased in both $\mathrm{MO}$ injected exposure groups when compared with their respective uninjected controls (Figure 2).

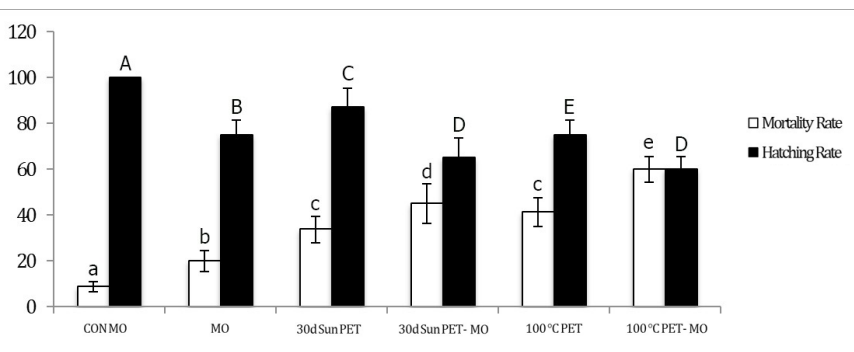

Figure 2. Mortality rates and hatching rates of embryos, $n=20$, The average values were obtained from three experiments. Data presented are mean $\pm S D$, Different letters within columns indicate statistically significant differences in the mortality rate (lower case) or hatching rate (upper case) as determined by One-way Anova followed by post-hoc Tukey's Multiple Comparision.

Immunohistochemical analysis revealed increased intensity of PCNA in neural tube, brain and eye; $\beta$-catenin in notochord and somites, Wnt $3 a$ in eye, brain and notochord in the 30 days sun exposed; PCNA in eye, neural tube, notochord and somites, $\beta$-catenin in eye, brain, neural tube, Wnt 3a in eye, brain, notochord and somites in the $100{ }^{\circ} \mathrm{C}$ boiled water filled PET bottles especially in the MO injected groups (Figure $3 \mathrm{~A}$ ).
A

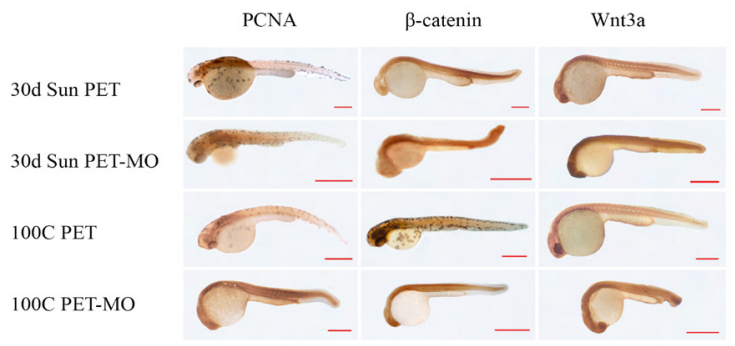

B

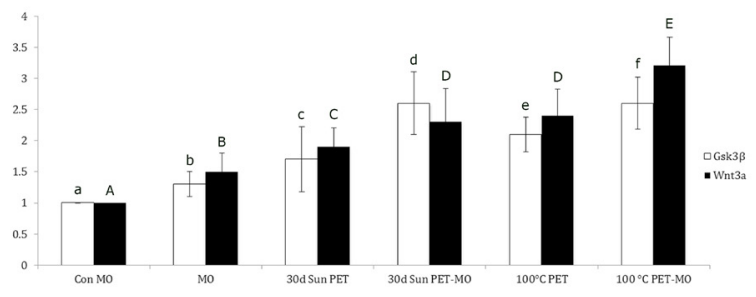

Figure 3. A) Immunohistochemical analysis of the expression of PCNA, B-catenin, Wnt 3a, Control Morpholino images are given in Figure 1. B) Quantitative expression of wht $3 a$ and gsk3B expressed as fold increases in 30 days direct sun light exposed PET group (30d Sun PET), $100^{\circ} \mathrm{C}$ boiled water filled PET group $\left(100^{\circ} \mathrm{C} P E T\right)$, and APC morpholino embryos corresponding to the exposure groups (MO). Increased expressions were observed in the exposure groups but yet increases more evident in the APC morphant embryos. Data presented are mean $\pm S D$. Different letters within columns indicate statistically significant differences in the expressions of Gsk3B (lower case) or Wnt $3 a$ (upper case) as determined by One-way Anova followed by post-hoc Tukey's Multiple Comparision. Con: Control, MO: Morpholino, PET: Polyethylene terephthalate

The wnt3a and gsk3B expressions were found to be elevated given as fold increases with the 6 -actin gene being used for normalization. Significant increases were observed in wnt3a and gsk3b expressions in the MO group when compared the Con MO group. The expressions of wnt3a and gsk3B in $\mathrm{MO}$ injected $30 \mathrm{~d}$ Sun PET and PET $100^{\circ} \mathrm{C}$ exposed embryos increased significantly when compared with their uninjected controls (Figure 3B).

Results of total phthalates analyses in the water samples are given as the mean concentration of three replicates in Table 1. Phthalate levels in the control PET bottle was below the detection limits of the assay used in this study. On the other hand, total phthalate levels increased to the detection limit of the assay in the exposure groups, $100^{\circ} \mathrm{C}$ boiled water filled $(9,63 \pm 1,3 \mu \mathrm{g} / \mathrm{L})$ and 30 days direct sunlight exposed PET bottles $(8,45 \pm 1,28 \mu \mathrm{g} / \mathrm{L})$ (Table 1$)$. The concentrations of vitellogenin, nitric oxide and lipid peroxidation increased significantly whereas glutathione S-transferase decreased in the exposure groups when compared with the control group (Table 2). According to the acridine orange staining results there were considerable numbers of apoptotic cells in the exposure groups mainly in the head and eye region (Figure 4). 
Table 1. Total phthalates concentrations in drinking water samples in PET and PC bottles

Total Phytalates Concentration in PET Bottles $(\mathrm{ng} / \mathrm{ml})$

\begin{tabular}{|l|l|}
\hline Control PET bottle & ND \\
\hline 30 days direct sunlight exposed PET bottle & $8,45 \pm 1,28$ \\
\hline $100^{\circ} \mathrm{C}$ boiled water filled PET bottle & $9,63 \pm 1,3$ \\
\hline
\end{tabular}

Data presented are mean \pm SD. ND: Not detected, PET: Polyethylene terephthalate

Table 2. Vitellogenin, nitric oxide, lipid peroxidation and glutathione-S transferase levels of the zebrafish embryos

\begin{tabular}{|l|l|l|l|l|}
\hline & $\begin{array}{l}\text { Vitellogenin } \\
(\mathrm{ng} / \mathrm{mL})\end{array}$ & $\begin{array}{l}\text { NO } \\
\text { (n mol/mg } \\
\mathrm{P})\end{array}$ & $\begin{array}{l}\text { GST } \\
(\mathrm{U} / \mathrm{g} \text { P) }\end{array}$ & $\begin{array}{l}\text { LPO } \\
\text { ( } \mu \mathrm{mol} \\
\text { MDA/g P) }\end{array}$ \\
\hline Control & $59,8 \pm 5,7$ & $13,44 \pm 1,9$ & $0,41 \pm 0,022$ & $0,028 \pm 0,002$ \\
\hline 30d PET & $92,6 \pm 6,3^{\mathrm{a}}$ & $21,34 \pm 3,6^{\mathrm{b}}$ & $0,23 \pm 0,01^{\mathrm{a}}$ & $0,035 \pm 0,002^{\mathrm{d}}$ \\
\hline 100 $^{\circ}$ PET Group & $108,8 \pm 9,4^{\mathrm{a}}$ & $24,76 \pm 3,72^{\mathrm{c}}$ & $0,23 \pm 0,012^{\mathrm{a}}$ & $0,032 \pm 0,003^{\mathrm{e}}$ \\
\hline
\end{tabular}

Data presented are mean \pm SD. NO: Nitric oxide; GST: Glutathione-S transferase; LPO Lipid peroxidation. Significant differences from the control group are indicated by letters, ${ }^{a} p<0,0001 ;{ }^{b} p=0,0046 ;{ }^{c} p=0,0003 ;{ }^{d} p=0,0004 ;{ }^{e} p=0,021$
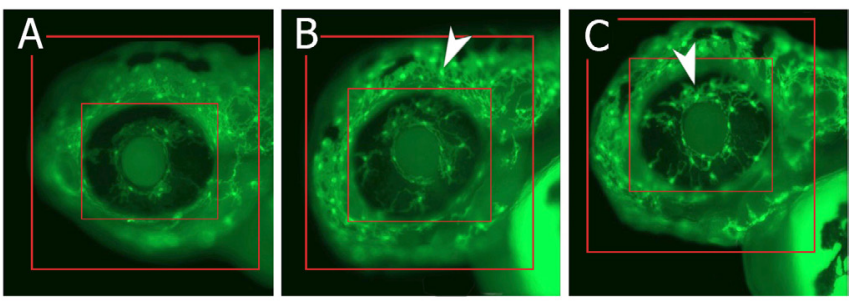

Figure 4. Apoptotic cells were observed in the head and retina region of the zebrafish embryos. A) Control Group, B) $30 \mathrm{~d}$ Sun Exposed PET, C) $100^{\circ} \mathrm{C}$ heated PET Group. Small square: eye region; Big square:head region, PET: Polyethylene terephthalate

\section{DISCUSSION}

Use of plastic materials increased for bottled water production and PET is one of the most used polymer. But chemical migration of plasticisers and additives to water $(28,29)$ became a major health concern. Phthalates are used to improve flexibility and phthalate migration has been shown before (30-31).

Quantitative phthalate determination is challenging as phthalates do not persist in outdoor environment. Gas chromatography mass spectrometry is the most used technique but in the present study ELISA was used. Phthalate levels were below the detection limit for control PET bottled water samples but increased in exposure groups. Increased DEHP concentrations due to poor storage conditions have been reported before (31-33).

DEHP is a potential carcinogen and toxic to reproductive organs, kidneys and liver (7,34-37). Zebrafish (Danio rerio) is used for studying the effects of environmental toxins (38). To examine the hypothesis that APC knockdown embryos were more prone to the effects of chemicals that leach from PET bottles we aimed to knock down APC function. Mutations in the Wnt pathway are related with birth defects, cancer and other diseases (39). Genetic mutations in APC and $\beta$-catenin way lead to activation of canonical signaling as the protein product of $A P C$ gene is a key component of the $\beta$-catenin destruction complex (40).

The expressions of wht $3 a$ and gsk3b increased significantly in the 30 days sunlight exposed and $100{ }^{\circ} \mathrm{C}$ boiled water filled PET bottle groups and increases were more profound in the APC knockdown groups. Mutations in APC result in the accumulation of $\beta$-catenin and stimulate proliferation genes like c-myc (26). In our study PCNA was evaluated as a proliferation marker and increased expressions were observed in the APC morphant exposure group. $\beta$-catenin's abnormal expression causes various diseases including cancer (41). $\beta$-catenin expression increased in exposure groups especially in APC knockdown groups. Acridine orange staining showed that apoptotic cells mainly accumulated in the head region which indicates possible EDC induced impairments in this region through the aryl hydrocarbon receptor (AhR) (42). Oxidant-antioxidant balance was impaired and NO levels increased in the exposure groups. There are conflicting roles of NO in proapoptotic pathways (43-45). Increased gsk38 expressions may be related with apoptosis through the inhibition of prosurvival transcription factors, and activation of proapoptotic transcription factors $(46,47)$.

Vitellogenin genes are expressed in an estrogen-dependent manner therefore only mature females are able to produce vitellogenin in larger quantities. On the other hand estrogenic molecules trigger vitellogenin synthesis in males and larvae as well (48-50). In this study vitellogenin levels increased in exposure groups. DEHP's estrogenic activity is still unclear $(50,51)$. We have previously shown that $\operatorname{DEHP}(2,5 \mu \mathrm{g} / \mathrm{L}) \mathrm{did}$ not increase vitellogenin levels in zebrafish embryos (52). Increased vitellogenin levels in exposure groups may be due to higher concentration of phalates in water samples or other chemicals that may have migrated into water from PET bottles.

\section{CONCLUSION}

The results of this study demonstrate that poor storage conditions increase phthalate concentrations in PET bottled water samples through photolysis $(53,54)$ and $A P C$ knockdown embryos were more prone to the deleterious effects of these water samples. Therefore although the determined phthalate concentrations are not yet a thread for human health, their striking effects on zebrafish embryo should be taken into account and appropriate storage conditions should be promoted for public health.

Disclosure Statement:No competing financial interests exist.

Financial Disclosure: This project was supported by TUBITAK Project Number: 114S537; Scientific Research Project Commission of Marmara University Project No: SAG-E-120.314.0056 and SAG-C-YLP-200.716.0370. 


\section{REFERENCES}

[1] Kortenkamp A, Faust M, Scholze M, Backhaus T. Low-level exposure to multiple chemicals: reason for human health concerns? Environ Health Perspect 2007; 115(Suppl 1):106114.

[2] Diamanti-Kandarakis E, Bourguignon JP, Giudice LC, Hauser R, Prins GS, Soto AM, Zoeller RT, Gore AC. Endocrine-disrupting chemicals: an Endocrine Society scientific statement. Endocr Rev 2009;30(4):293-342.

[3] Uzumcu M, Zama AM, Oruc E. Epigenetic mechanisms in the actions of endocrine-disrupting chemicals: gonadal effects and role in female reproduction. Reprod Domest. Animals. 2012; 4:338-347.

[4] Muncke J. Exposure to endocrine disrupting compounds via the food chain: Is packaging a relevant source? Sci Total Environ 2009;1: 407(16):4549-4559.

[5] Sax L. Polyethylene Terephthalate May Yield Endocrine Disruptors. Environ Health Perspect 2010; 18(4):445-448.

[6] Grün F, Blumberg B. Endocrine disrupters as obesogens. Mol Cell Endocrinol 2009;25:304(1-2):19-29.

[7] Swan SH, Main KM, Liu F, Stewart SL, Kruse RL, Calafat AM, Mao CS, Redmon JD, Ternand CL, Sullivan S, Teague JL. Decrease in anogenital distance among male infants with prenatal phthalate exposure. Environ Health Perspect. 2005; 113:1056-61.

[8] Pan G, Hanaoka T, Yoshimura M, Zhang s, Wang P, Tsukino H, Inoue K, Nakazawa H, Tsugane S, Takahashi K. Decreased serum free testosterone in workers exposed to high levels of di-nbutyl phthalate (DBP) and di-2-ethylhexyl phthalate (DEHP): a cross-sectional study in China. Environ Health Perspect 2006; 114(11):1643-1648.

[9] Hauser R, Calafat AM. Phthalates and human health. Occup Environ Med. 2005; 62(11):806-818.

[10] Latini G, Verrotti A, Felice C. DI-2-Ethylhexyl phthalate and endocrine disruption: A Review. Curr Drug Targets Immune Endocr Metabol Disord 2004; 4: 37-40.

[11] Muncke J. Endocrine disrupting chemicals and other substances of concern in food contact materials: An updated review of exposure, effect and risk assessment. J Steroid Biochem Mol Biol 2011; 127: 118- 127.

[12] Eisinger AL, Nadauld LD, Shelton DN, Peterson PW, Phelps RA, Chidester S, Stafforini DM, Prescott SM, Jones DA. The adenomatous polyposis coli tumor suppressor gene regulates expression of cyclooxygenase-2 by a mechanism that involves retinoic acid. J Biol Chem 2006;, 21:281(29):20474-20482.

[13] Goss KH and Groden J. Biology of the adenomatous polyposis coli tumor suppressor. J Clin Oncol 2000; 18(9):1967-1979.

[14] Shojima K, Sato A, Hanaki H, Tsujimoto I, Nakamura M, Hattori K, Sato Y, Dohi K, Hirata M, Yamamoto H, Kikuchi A. Wnt5a promotes cancer cell invasion and proliferation by receptormediated endocytosis-dependent and - independent mechanisms, respectively. Sci Rep 2015; 27;5:8042.

[15] Shojima K, Sato A, Hanaki H, Tsujimoto I, Nakamura M, Hattori K, Sato Y, Dohi K, Hirata M, Yamamoto H, Kikuchi A. Wnt5a promotes cancer cell invasion and proliferation by receptor-mediated endocytosis-dependent and independent mechanisms, respectively. Sci Rep 2015;27;5:8042.

[16] Mudbhary R and Sadler KC. Epigenetics, development, and cancer: zebrafish make their mark. Birth Defects Res C Embryo Today.2011; 93(2):194-203.
[17] Westerfield M. The Zebrafish Book: A Guide for the Laboratory Use of Zebrafish, University of Oregon Press.,1995; Eugene, OR.

[18] Draper BW, Morcos PA, Kimmel CB.Inhibition of zebrafish fgf8 pre-mRNA splicing with morpholino oligos: a quantifiable method for gene knockdown. Genesis 2001; 30(3):154-156.

[19] Livak KJ, Schmittgen TD. Analysis of Relative Gene Expression Data Using Real - Time Quantitative PCR and the $2^{\Delta \Delta} \mathrm{CT}$ Method. METHODS.2001; 25: 402-408.

[20] Lowry OH, Rosebrough NJ, Farr AL, Randall RJ. Protein measurement with the Folin phenol reagent. J Biol Chem 1951;193(1):265-275.

[21] Yagi K. Assay for blood plasma or serum. Methods Enzymol. 1984; 105:328-331.

[22] Miranda KM, Espey MG, Wink DA. A rapid, simple spectrophotometric method for simultaneous detection of nitrate and nitrite. Nitric Oxide 2001;5(1):62-71.

[23] Habig WH, Pabst MJ, Jakoby WB. Glutathione S-transferases. The first enzymatic step in mercapturic acid formation. J Biol Chem. 1974, 25;249(22):7130-7139.

[24] Tucker B, Lardelli M. A rapid apoptosis assay measuring relative acridine orange fluorescence in zebrafish embryos. Zebrafish 2007;4(2):113-116.

[25] Nadauld LD, Sandoval IT, Chidester S, Yost HJ, Jones DA. Adenomatous polyposis coli control of retinoic acid biosynthesis is critical for zebrafish intestinal development and differentiation. J Biol Chem. 2004; 279: 51581-51589.

[26] He TC, Sparks AB, Rago C, Hermeking H, Zawel L, Da Costa LT, Morin PJ, Vogelstein B, Kinzler KM. Identification of c-MYC as a target of the APC pathway. SCIENCE 1998; 281:1509-1512.

[27] Stafford D, Prince VE. Retinoic acid signaling is required for a critical early step in zebrafish pancreatic development. Curr Biol 2002; 23:12(14):1215-1220.

[28] Biscardi D, Monarca S, De Fusco R, Senatore F, Poli P, Buschini A, Rossi C, Zani C. Evaluation of the migration of mutagens/carcinogens from PET bottles into mineral water by Tradescantia/micronuclei test, Comet assay on leukocytes and GC/MS. Sci Tot Environ 2003, 302:101-108.

[29] Diana A and Dimitra V. Alkylphenols and phthalates in bottled waters. J Hazard Mater 2011; 185: 281-286.

[30] Peñ alver A, Pocurull E, Borrull F, Marce' RM. Determination of phthalate esters in water samples by solid-phase microextraction and gas chromatography with mass spectrometric detection. J Chromatogr A 2000; 872:191-201.

[31] Casajuana $\mathrm{N}$ and Lacorte $\mathrm{S}$. Presence and release of phthalic esters and other endocrine disrupting compounds in drinking water. Chromatographia 2003; 57:649-655.

[32] Leivadara SV, Nikolaou AD, Lekkas TD. Determination of organic compounds in bottled waters. Food Chem. 2008; 108:277-86.

[33] Keresztes S, Tatár E, Czégény Z, Záray G, Mihucz VG. Study on the leaching of phthalates from polyethylene terephthalate bottles into mineral water. Study on the leaching of phthalates from polyethylene terephthalate bottles into mineral water. Sci Total Environ 2013; 458-460: 451-458.

[34] Gomez-Hens A and Aguilar-Caballos MP. Social and economic interest in the control of phthalic acid esters. TrAC 2003; 22:847-857.

[35] Plotan M, Frizzell C, Robinson V, Elliott CT, Connolly L Endocrine disruptor activity in bottled mineral and flavoured water. Food Chem. 2012; 136: 1590-1596. 
[36] Pinto B and Reali D. Screening of estrogen-like activity of mineral water stored in PET bottles. Int J Hyg Environ Health 2009; 212:228-232.

[37] Wagner $M$ and Oehlmann J. Endocrine disruptors in bottled mineral water: total estrogenic activity in the E-screen. J Steroid Biochem Mol Biol 2011; 127:128-135.

[38] Yang Y, Qi S, Wang D, WangK, Zhu L, Chai T, Wang C. Toxic effects of thifluzamide on zebrafish (Danio rerio). J Hazard Mater. 2016:15;307:127-136.

[39] Logan CY, Nusse R. The Wnt signaling pathway in development and disease. Ann. Rev. Cell and Develop Biol. 2004; 20: 781 810.

[40] Najdi R, Holcombe RF, Waterman ML. Wnt signaling and colon carcinogenesis: beyond APC J. Carcinog 2011; 17:10:5.

[41] Thakur R and Mishr DP. Pharmacological modulation of betacatenin and its applications in cancer therapy. J Cell Mol Med 2013; 17(4): 449-456.

[42] Frye C, Bo E, Calamandrei G, Calzà L, Dessì-Fulgheri F, Fernández M, Panzica GC. Endocrine disrupters: A review of some sources, effects, and mechanisms of actions on behavior and neuroendocrine systems. J Neuroendocrinol. 2012; 24(1): 144-159.

[43] Brüne B. Nitric oxide: NO apoptosis or turning it ON? Cell Death Differ. 2003;10(8):864-869.

[44] Pećina-Šlaus N. Wnt signal transduction pathway and apoptosis: a review. Cancer Cell Int 2010; 10:22.

[45] GuiSS, Yuan G, Wang L. Wnt3a regulates proliferation, apoptosis and function of pancreatic NIT-1 beta cells via activation of IRS2/PI3K signaling. J. Cellular Biochem. 2013;114:1488-1497.

[46] Grimes CA and Jope RS. The multifaceted roles of glycogen synthase kinase $3 \beta$ in cellular signaling. Prog Neurobiol 2001, 65(4): 391-426.
[47] Watcharasit P, Bijur GN, Zmijewski JW. Direct, activating interaction between glycogen synthase kinase-3 $\beta$ and p53 after DNA damage. Proc Natl Acad Sci USA 2002; 99(12): 7951-7955.

[48] Wallace RA, Jared DW. Studiesonamphibiayolk.VII. Serumphosphopro - tein synthesis by vitellogenic females and estrogen-treated males of Xenopus laevis. Can J Biochem 1968; 46: 953-959.

[49] Lazier CB and McKay ME. Vitellogenin gene expression in teleost fish. Biochemistry and Molecular Biology of Fishes 1993;2:391-405.

[50] Bakos K, Kovács R, Stasznya A, Siposa DK, Urbányia B, Müller F, Csenkia Z, Kovács B. Developmental toxicity and estrogenic potency of zearalenone in zebrafish (Danio rerio). Aquat Toxicol 2013 136-137 (2013) 13-21.

[51] Uren-Webster TM, Lewis C, Filby AL, Paull GC, SantosEM. Mechanisms of toxicity of di(2-ethylhexyl) phthalate on the reproductive health of male zebrafish. Aquat Toxicol 2010; 99: 360-369.

[52] Ustundag UV, Unal I, Ates PS, Alturfan AA, Yigitbasi T, EmekliAlturfan E. Bisphenol A and di(2-ethylhexyl) phthalate exert divergent effects on apoptosis and the $W n t / \beta$-catenin pathway in zebrafish embryos: A possible mechanism of endocrine disrupting chemical action. Toxicol Ind Health 2017; 33(12):901-910.

[53] Golshan M, Hatef A, Socha M, Milla S, Butts IAE, Carnevali O, Rodina M Sokołowska-Mikołajczyk M, Fontaine P, Linhart O, Alavi SMHD. Di-(2-ethylhexyl)-phthalate disrupts pituitary and testicular hormonal functions to reduce sperm quality in mature goldfish. Aquat Toxicol 2015;163:16-26.

[54] Peterson DR and Charles AS. Degradation of phthalate esters in the environment. Handb Environ Chem 2003;85-124.

How to cite this article: Ustundag U. V., Unal I., Ates P. S., Tirpanc A., Egilmezer G., Alturfan A. A., Yigitbasi T., Emekli-Alturfan E. Effects of Water Samples in Polyethylene Terephthalate Bottles Stored at Different Conditions on Zebrafish Embryos with Relevance to Endocrine Disrupting Chemical Migration and Adenomatous Polyposis Coli Tumor Suppressor Gene. Clin Exp Health Sci 2019; 9: 171-177. DOI:10.33808/clinexphealthsci 564016 